\title{
Bumerang Kerjasama EU-Turkey Joint Action Plan Terkait Penanganan Krisis Pengungsi Terhadap Turki
}

Fitri Sholihin ${ }^{1}$, Rama Fernandhy Alfan ${ }^{2}$

fitriakantu@gmail.com, fernandhyya@gmail.com

${ }_{1}^{1}$ Pascasarjana Program Studi Hubungan Internasional, Universitas Airlangga Surabaya

${ }^{2}$ Pascasarjana Program Studi Hubungan Internasional, Universitas Airlangga Surabaya

DOI: $10.22219 /$ sospol.v7i2.16098

\begin{tabular}{|c|c|}
\hline $\begin{array}{l}\text { Abstract } \\
\text { This paper analyzes the governance of Syrian refugees in Turkey and the } \\
\text { cooperative relationship between the European Union and Turkey } \\
\text { regarding the handling of refugees. The mass migration from Syria has } \\
\text { been a major turning point in EU-Turkey relations. Through the Syrian } \\
\text { mass in 2011, Turkey implemented an open-door policy to the problem. } \\
\text { In 2013, the EU began offering assistance to share the shared burden of } \\
\text { the complex refugee crisis with an action plan. Through the action plan, } \\
\text { Turkey began to use refugee foreign policy tools to meet EU } \\
\text { requirements. Turkey began to act as an opportunistic suppressor by } \\
\text { using the problem of the refugee crisis to "benefit" from the action plan. } \\
\text { However, instead of making a profit, Turkey must take on the "burden" } \\
\text { of refugees to help and provide some aid. } \\
\text { Abstrak } \\
\text { Tulisan ini menganalisis tentang tata kelola pengungsi Suriah di Turki dan } \\
\text { hubungan kerja sama antara Uni Eropa dan Turki tentang penanganan } \\
\text { krisis pengungsi. Migrasi massal dari Suriah telah menjadi titik balik utama } \\
\text { dalam hubungan Uni Eropa dan Turki. Melalui migrasi massal Suriah } \\
\text { pada tahun 2011, Turki menerapkan open door policy guna menangani } \\
\text { masalah tersebut. Pada tahun 2013, Uni Eropa mulai menawarkan } \\
\text { bantuan untuk berbagi beban bersama menangani krisis pengungsi } \\
\text { tersebut yang dilanjutkan dengan action plan. Melalui action plan tersebut, } \\
\text { Turki mulai menggunakan pengungsi sebagai alat kebijakan luar negeri } \\
\text { yang memaksa yang digunakan untuk menentang persyaratan Uni Eropa. } \\
\text { Turki mulai bertindak sebagai penekan oportunistik dengan } \\
\text { menggunakan masalah krisis pengungsi untuk mendapat "keuntungan" } \\
\text { dari action plan tersebut. Namun, alih-alih mendapat keuntungan, Turki } \\
\text { harus menanggung "beban" pengungsi sendirian untuk menampung dan } \\
\text { memberikan bantuan. }\end{array}$ & $\begin{array}{l}\text { Article History } \\
\text { Received August 23, } 2021 \\
\text { Revised November 21, } 2021 \\
\text { Accepted November 29, } 2021 \\
\text { Published November 30, } 2021\end{array}$ \\
\hline
\end{tabular}

\section{Pendahuluan}

Sejak tahun 2019, Presiden Turki, Recep Tayyip Erdogan, telah memperingatkan Eropa bahwa Turki tidak dapat menangani gelombang baru pengungsi Suriah yang melarikan diri dari pemboman. Sebanyak 80 ribu warga Suriah telah melarikan diri ke perbatasan Turki, Idlib, menyusul peningkatan rezim dan pemboman Rusia di wilayah Maaret al-Numan. Saat ini, Turki menampung populasi pengungsi terbesar di dunia. Menurut data laporan UNHCR, pada tahun 2018 Turki telah menampung sekitar 4 juta pengungsi, di mana 3,6 juta di antaranya adalah warga Suriah (UNHCR, 2019). Pemerintah Turki memperkirakan jumlah total warga Suriah yang 
terdaftar di bawah Suriahns under Temporary Protection (SuTPs) 2.225.147 juta orang (World Bank, 2019).

Sebelumnya, pada 18 Maret 2016, Turki dan Uni Eropa sepakat dengan menandatangani perjanjian dalam mengatasi masalah krisis pengungsi secara bersama-sama. Perjanjian tersebut sebagai upaya untuk memecahkan salah satu masalah paling mendesak di Eropa yaitu gelombang besar pengungsi. Menurut pernyataan Uni Eropa-Turki, semua migran gelap dan pencari suaka yang tiba dari Turki dan yang permohonan suaranya telah dinyatakan tidak dapat diterima harus dikembalikan ke Turki.

Adapun kesepakatan lainnya yaitu, 1) Untuk setiap warga Suriah yang kembali ke Turki dari pulau-pulau Yunani, warga Suriah lainnya akan dipindahkan ke Uni Eropa, 2) Turki akan mengambil langkah-langkah yang diperlukan untuk mencegah rute laut atau darat untuk pembukaan gelombang migrasi tidak teratur dari Turki ke Uni Eropa, dan 3) Uni Eropa akan, dalam kerja sama erat dengan Turki, dan berkomitmen memberikan bantuan dana sebesar 6 miliar USD untuk Turki (European Commision, 2015).

Setelah tahun pertama, kesepakatan itu tampaknya berhasil mencapai tujuan utamanya yaitu menghalangi aliran pengungsi dan migran untuk memasuki Uni Eropa. Turki mulai memberlakukan pembatasan visa bagi warga Suriah yang datang melalui udara dan laut dan membangun tembok perbatasan 700 kilometer sebagai upaya untuk mengamankan perbatasan UE-Turki. Hal ini untuk mematuhi perjanjian dari tahun 2016 dan untuk menghindari masuknya pengungsi yang kembali yang terdiri dari pencari suaka tidak sah yang dikirim kembali ke Turki dari negara-negara anggota UE (Olejarova, 2018).

Namun, hubungan kerja sama tersebut mengalami ketegangan ketika Uni Eropa dan Turki saling tuduh. Turki menuduh Uni Eropa melakukan keterlambatan pembayaran, sementara Uni Eropa menuduh bahwa Turki tidak berpegang teguh pada akhir kesepakatan dan melonggarkan kontrol keamanan pada rute migrasi. Erdogan menyampaikan jika aliran pengungsi tersebut terus meningkat, hal tersebut akan memberikan tambahan beban dan memberikan "peringatan" kepada Uni Eropa bahwa Turki tidak akan memikul beban tersebut sendirian diikuti dengan "ancaman" akan mengizinkan pengungsi untuk melanjutkan perjalanan ke Eropa.

Berdasarkan latar belakang tersebut, penulis kemudian mengangkat sebuah rumusan masalah yakni "Bagaimana joint action plan krisis pengungsi global dengan Uni Eropa menjadi sebuah bumerang untuk Turki ?" Penulis berpendapat bahwa masalah krisis pengungsi global telah mempengaruhi beberapa negara di dunia dan tentunya membutuhkan aksi bersama untuk menyelesaikan krisis tersebut. Negara-negara berbagi beban keuangan untuk membantu negaranegara lainnya yang menerima pengungsi. Sistem bantuan kemanusiaan diorganisasikan oleh beberapa lembaga internasional, seperti United Nations High Commissioner for Refugees (UNHCR) dan non governmental organization (NGO) di mana negara-negara mendukung lembagalembaga tersebut dengan menyediakan dana memberi makan, menyediakan layanan, dan melindungi para pengungsi.

Tak jarang juga negara-negara menunjukkan solidaritasnya dengan berbagi tanggung jawab untuk menerima pengungsi secara fisik di mana negara tidak mengembalikan pengungsi ke tempat asal mereka. Namun, saat ini beberapa negara mulai melarang pengungsi untuk masuk ke negaranya dengan alasan keselamatan dan keamanan yang akhirnya membuat negara tersebut mencari negara "pengganti" untuk menampung pengungsi tersebut dengan memberikan janji keuntungan. 
Namun, tak semua negara "pengganti" ini mendapatkan keuntungan seperti yang dijanjikan dan justru mendapatkan "kerugian". Berangkat dari paparan diatas, penelitian ini berupaya memaparkan bagaimana efek timbal balik yang diterima Turki, sebagai konsekuensi dari berlakunya EU-Turkey Joint Action Plan. Guna memudahkan analisa, penelitian ini menggunakan coercive engineered migration (CEM) dan suasion game sebagai kerangka konseptual.

Kelly Greenhill (2016) menguraikan coercive engineered migration atau gerakan populasi lintas batas yang sengaja dibuat atau dimanipulasi yang sering dilakukan negara-negara lemah atau aktor non-negara untuk mendorong adanya izin politik, militer dan ekonomi dari negara target, negara bagian atau organisasi internasional. Negara-negara oportunistik sebagai subkategori aktor yang menggunakan paksaan, namun, tidak memainkan peran langsung dalam penciptaan krisis migrasi, tetapi hanya mengeksploitasi mereka dalam mengejar tujuan kebijakan mereka. Misalnya, oportunis mungkin mengancam untuk menutup perbatasannya kecuali target mengambil tindakan yang diinginkan, seperti yang terjadi pada Turki. Kadang-kadang kaum oportunis menawarkan untuk meringankan krisis yang ada dengan kompensasi politik atau moneter (Greenhill, 2016).

Negara-negara sasaran, sebaliknya, memiliki serangkaian tuntutan yang saling terkait yang lebih kompleks, seperti memungkinkan masuknya pengungsi yang terdampar di perbatasan ke negara mereka, memfasilitasi akses para pengungsi ke pendidikan dan lapangan kerja untuk menjaga mereka tetap di dalam negara mereka, dan pengontrolan perbatasan yang ketat untuk mencegah pergerakan lebih lanjut menuju negara tujuan. Negara "pemaksa" biasanya akan mencari bantuan keuangan untuk menutupi biaya penampungan pengungsi, bantuan pembangunan, izin perdagangan, insentif mobilitas, atau kemajuan dalam tujuan kebijakan luar negeri jangka panjang lainnya. Dengan kata lain, negara "pemaksa" melihat tawar-menawar atas kontrol migrasi sebagai jendela peluang untuk memperoleh keuntungan yang tidak dapat dicapai.

Sejak gelombang pengungsi Suriah setelah tahun 2011, Turki telah mulai menerapkan aturan-aturan Uni Eropa. Sejak saat itu juga, Uni Eropa mulai menawarkan bantuannya melalui action plan yang dianggap sebagai mekanisme baru untuk menahan pengungsi datang ke Eropa. Karena tanpa kolaborasi Turki, Uni Eropa tidak dapat mengelola gelombang pengungsi tersebut dengan cara yang sesuai dengan tujuannya. Tuntutan Uni Eropa untuk Turki telah berlipat ganda, seperti (1) mendukung kontrol perbatasan eksternal Uni Eropa melalui manajemen perbatasan terintegrasi dan mengendalikan penyelundupan, dan (2) menyelaraskan kebijakan visa dan secara efektif mengimplementasikan perjanjian penerimaan kembali, selain mengangkat batasan geografis pada Konvensi Pengungsi 1951. Sebagai imbalannya, Turki telah dijanjikan pembangunan kapasitas dan dukungan finansial, pembebasan visa, dan keanggotaan penuh Uni Eropa bila syaratsyarat aksesi lainnya terpenuhi (Aras dan Mencutek, 2018).

Sementara itu the Suasion Game didefinisikan ketika dalam model dua aktor, terdapat satu pemain yang lebih kuat dan memiliki sedikit minat untuk bekerja sama, dan satu aktor yang lebih lemah dan memiliki sedikit pilihan selain bekerja sama (Betts, 2011). Ciri khas The Suasion Game adalah "pemain" memiliki hasil keseimbangan tunggal, yang hanya memuaskan satu aktor dan membuat yang lain dirugikan, dengan kata lain hanya satu aktor menerima hasil yang sesuai, sementara yang lain tidak (Diez et.al, 2011).

Konsep tersebut melibatkan dua aktor, satu aktor yang lebih lemah A (negara bagian penerima suaka pertama di Selatan) dan satu aktor yang lebih kuat B (negara bagian donor Utara). Karena kekuatan relatif mereka yang berbeda, kedua aktor memiliki kepentingan yang berbeda 
(Betts, 2011). Situasi tersebut dapat direpresentasikan dalam game theory dengan salah satu dari dua cara. Salah satu aktor (lebih lemah), memiliki strategi dominan untuk bekerja sama, yang dapat dieksploitasi oleh pihak lain (yang lebih kuat), atau satu aktor (yang lebih kuat) memiliki strategi dominan untuk membelot, sementara yang lain harus bekerja sama untuk menghindari hasil yang lebih buruk (Hassenclever et.al, 2004).

Penelitian ini menjadi sebuah contoh dari hasil akhir the suasion game yaitu, kerja sama yang tidak terbalas. Turki menjadi aktor A yang menggunakan strategi kerja sama dengan menerima tawaran Uni Eropa untuk beban berbagi terhadap pengungsi, yang membuat Turki "lebih menyakiti diri sendiri”" daripada dengan tidak bekerja sama sama sekali.

\section{Metode}

Metode penelitian yang digunakan dalam tulisan ini adalah metode analisa data yang bersifat kualitatif, yaitu penelitian yang menggambarkan isi tetapi tidak berdasarkan akurasi statistik. Menganalisis masalah berdasarkan fakta-fakta yang kemudian menghubungkan fakta tersebut dengan fakta lainnya sehingga menghasilkan sebuah argumen yang tepat (Ulber, 2012). Metode kualitatif digunakan untuk menjawab pertanyaan tentang pengalaman, makna dan perspektif, paling sering dari sudut pandang peserta (Hammarberg et.al, 2016). Teknik yang digunakan oleh penulis adalah induktif, yaitu sebuah proses yang dimulai dengan topik, menghasilkan hipotesis dan mengumpulkan datanya, kemudian menganalisa data dan dari analisis ini muncul penjelasan teoretis tentang fenomena yang sedang diobservasi (Harrison \& Carlan, 2013).

Penelitian ini menggabungkan analisis data primer dan data sekunder. Data primer didapat dari dokumen-dokumen resmi (official documents) yang dirilis oleh Uni Eropa, sebagai contoh dokumen EU-Turkey Readmission Agreement dan juga EU-Turkey joint action plan. Sedangkan data sekunder diperoleh dari kajian-kajian literatur yang telah ada dan memiliki kontribusi terhadap penelitian ini, seperti: buku, jurnal, artikel, dokumen, surat kabar yang telah melalui triangulasi data sehingga dapat digunakan untuk mendukung keperluan penelitian.

\section{Hasil dan Pembahasan \\ Pengungsi Suriah di Turki}

Pengungsi adalah orang terlantar yang telah dipaksa untuk melintasi batas negara dan yang tidak dapat kembali ke rumah dengan selamat. Kata "pengungsi" secara resmi didefinisikan oleh Konvensi 1951 yang berkaitan dengan status pengungsi dan Protokol 1967. Konvensi Pasal 1 bagian A No.2 menyatakan bahwa seorang pengungsi adalah setiap orang yang:

\begin{abstract}
... owing to well-founded fear of being persecuted for reasons of race, religion, nationality, membership of a particular social group or political opinion, is outside the country of his nationality and is unable or, owing to such fear, is unwilling to avail bimself of the protection of that country; or who, not having a nationality and being outside the country of his former habitual residence as a result of such events, is unable or, owing to such fear, is unwilling to return to it (United Nations 1951).
\end{abstract}


Sesuai dengan definisi tersebut, semua pengungsi harus berada di luar negara kebangsaan mereka atau bekas tempat tinggal mereka. Pada tahun 2018, menurut data UNHCR, hampir 24,5 juta pengungsi di mana 20 juta di antaranya berada di bawah mandat UNHCR. Salah satu negara dengan sumber pengungsi paling besar yakni Suriah dengan 6,3 juta pengungsi yang menjadikannya sebagai negara dengan sumber utama terbesar (UNHCR, 2018).

Pada Maret 2011, protes anti-pemerintah meletus di Suriah dikarenakan adanya tindakan represif rezim Assad, seperti pengetatan sensor internet, perluasan penggunaan larangan perjalanan, dan penangkapan tahanan politik. Protes yang di inspirasi oleh protes serupa di Timur Tengah sebagai akibat dari Arab Spring ini menuntut pengunduran diri Presiden yang akhirnya Rezim Assad merespons secara agresif terhadap protes damai dengan memperburuk situasi (Olarewaju \& Joshua, 2015).

Pada akhir 2011, perang bersenjata dimulai antara pasukan pemerintah dan pemberontak oposisi. Dalam perang, pemerintah diadu melawan aliansi pemberontak oposisi terutama Sunni. Namun, perang tersebut telah meningkat karena campur tangan kekuatan global dan regional serta para Jihadis Islam (Khan, 2018).

Sejak 2011, perang saudara di Suriah telah menggusur sebanyak 12,5 juta orang. Suriah merupakan kelompok terbesar dalam 65,3 juta orang yang dipindahkan secara paksa di seluruh dunia. Populasi pengungsi besar lainnya termasuk Afghanistan, Sudan Selatan, Myanmar, dan Somalia. Seiring berlanjutnya perang di Suriah, jumlah warga Suriah telah meningkat di Turki dari tahun ke tahun (Gambar 1).

\section{Gambar 1. Kedatangan pengungsi Suriah ke Turki, 2012-2019.}

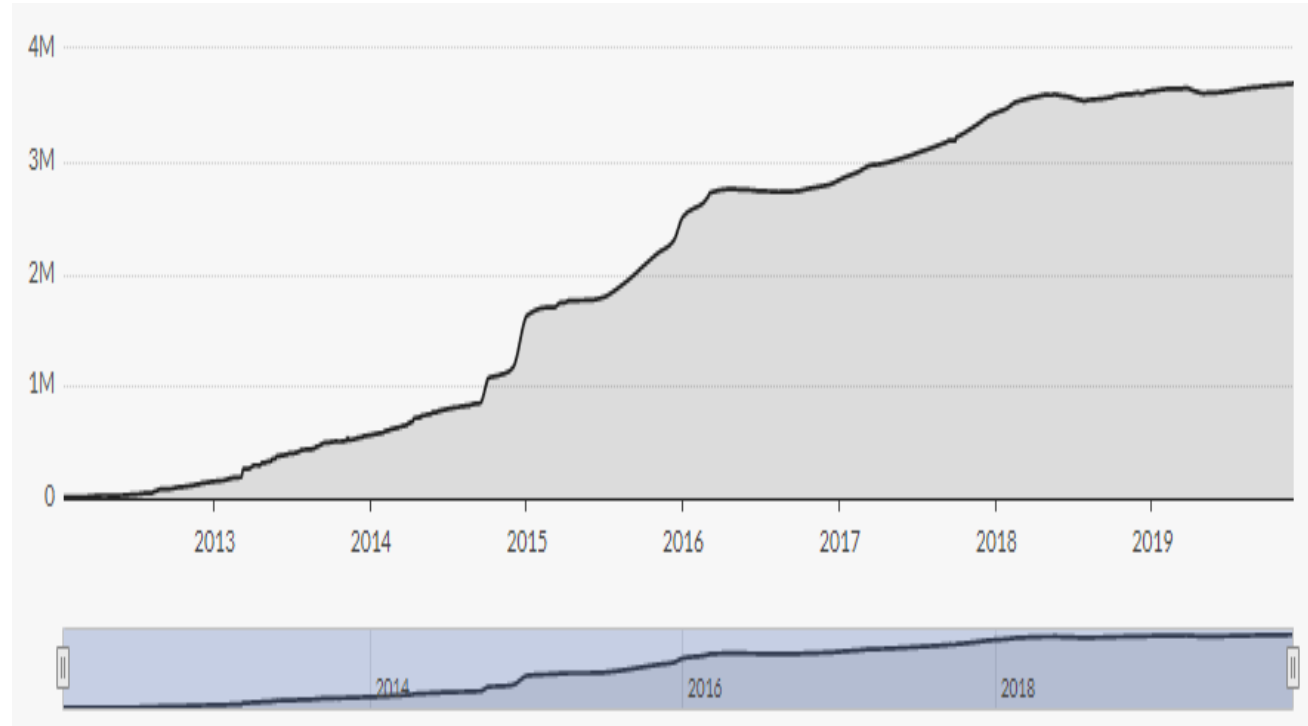

Source-UNHCR, Government of Turkey

\section{Sumber: UNHCR, 2019}

Turki telah menerapkan kebijakan terkait penerimaan pengungsi sejak tahun 1957, namun Turki hanya mengakui pengungsi yang berasal dari wilayah Eropa saja (Sefa et.al, 2017). Pengakuan ini didorong oleh beberapa hal Klausul 'pembatasan geografis' Turki. Meskipun Turki 
menandatangani Konvensi Jenewa Perserikatan Bangsa-Bangsa tahun 1951, Turki tetap mempertahankan klausul 'pembatasan geografis', yang berarti bahwa kewajibannya berlaku untuk pencari suaka dari Eropa, tetapi tidak untuk pengungsi non-Eropa (Yildiz, 2016).

Pencari suaka non-Eropa ditawarkan perlindungan de facto atau sementara seperti pada pengungsi Suriah di Turki. Status perlindungan sementara ini mengubah orang-orang tersebut menjadi migran transit atau migran yang terlantar sementara mereka menunggu permohonan pengungsi mereka dievaluasi atau mencari cara untuk masuk ke UE secara ilegal. Pada tahun 2012, jumlah warga Suriah di Turki mencapai 14.237 orang, kemudian mulai bertambah ditahun 2013 menjadi 224.665 orang. Pada tahun 2014, terjadi kenaikan yang drastis sebesar 1.519.286 pengungsi diikuti pada tahun 2015 sebesar 2.503.549 pengungsi (UNHCR, 2019).

\section{Kebijakan Turki terhadap Pengungsi Suriah}

Turki telah menjadi aktor global dan regional utama dalam hal migrasi internasional. Turki menampung pengungsi, orang-orang dengan status perlindungan sementara, dan migran gelap dari banyak negara. Pada tahun 2019, hampir 90 persen dari semua pengungsi yang berada di Turki, berasal dari Suriah. Tidak hanya itu, Turki juga telah menggelontorkan dana sebesar 37 miliar dollar untuk mengatasi lonjakan pengungsi melalui pembangunan camp pengungsian hingga tahun 2019 (Abdelaaty, 2019). Camp-camp pengungsian yang dibangun oleh Turki tersebar di beberapa wilayah di Turki seperti di Provinsi Hatay, Gaziantep, Sanliurfa, Kilis, Mardin, Kahramanmaras, Osmaniye, Adiyaman, Malatya, dan Adana (Syafitri, 2017).

Adapun faktor-faktor utama yang membentuk pergerakan migrasi ke Turki dan menjadikannya "hot spot" bagi para migran transit. Pertama, Icduygu (2000) mencatat bahwa kekacauan politik dan kekerasan yang terjadi di daerah tetangga mendorong orang-orang tersebut untuk mencari kondisi kehidupan yang lebih baik. Kedua, lokasi Turki antara Timur dan Barat yang secara politik dan ekonomi stabil dan makmur menjadikannya sebagai rute transit yang jelas dan tujuan yang menarik bagi para migran. Ketiga, prosedur penerimaan yang ketat dan kontrol imigrasi yang diperketat di Eropa telah mengalihkan arus imigrasi ke zona pinggiran di sekitar Eropa, termasuk Turki (Icduygu, 2013). Keempat, kemakmuran ekonomi relatif Turki menarik para migran, baik mereka yang memilih Turki sebagai negara tujuan dan juga mereka yang mencari peluang pendapatan untuk mendanai perjalanan selanjutnya (Icduygu, 2003).

Sementara negara-negara lain seperti Jordania dan Lebanon yang membatasi masuknya para pengungsi Suriah, pemerintah Turki tetap mempertahankan open door policy. Sebelumnya, Turki juga menerapkan open door policy ditahun 1991 ketika terjadi perang teluk kedua yang melibatkan pasukan Amerika dalam upayanya untuk menginvasi Irak ke Kuwait. Hingga pada akhirnya, kebijakan tersebut diterapkan kembali pada tahun 2011 yang bertepatan dengan terjadinya perang saudara antara kubu oposisi dan pemerintahan Bashar Al Assad di Suriah (Nielsen, 2016). Kebijakan ini memastikan untuk menghormati prinsip non-refoulement yaitu tidak memaksa pengungsi atau pencari suaka untuk kembali ke negara dan pemerintah berkomitmen untuk menyediakan kondisi kehidupan dan bantuan kemanusiaan terbaik bagi para pengungsi (Togral Koca, 2015).

Penerapan open door policy tersebut di dasari oleh beberapa faktor seperti faktor identitas dan "saudara seagama". Kesamaan identitas ini tidak bisa dilepaskan dari konflik antar kaum muslimin di Suriah, yang melibatkan rezim Bashar Al-Assad dan kelompok oposisi. Selain itu, Turki yang merupakan salah satu negara dengan mayoritas penduduknya beragama Islam. Open door Policy 
merupakan cerminan Turki yang peduli pada masyarakat yang memiliki kesamaan identitas yaitu identitas Islam (Koca, 2016).

Adanya faktor geografi juga mempengaruhi penerapan open door policy. Para pengungsi yang melarikan diri dari perang sering kali mencari perlindungan di sekitar negara asal. Lebih mudah untuk melarikan diri ke negara terdekat daripada melakukan perjalanan lebih jauh ke luar negeri (Olejarova, 2018). Suriah dan Turki memiliki letak geografis yang berdekatan dan juga berada pada lingkup kawasan yang sama yaitu wilayah Asia Barat. Selain itu, adanya komitmen Turki terhadap Konvensi Jenewa 1951 dan Protokol 1967 juga menjadi salah satu faktor open door policy.

Pada awalnya, penerapan kembali open doorpolicy sebagai respons awal pemerintah Turki yang didasarkan pada perencanaan darurat jangka pendek. Namun, Turki mulai mempertimbangkan kembali kebijakan migrasi karena jelas bahwa pengungsi Suriah tidak lagi hanya menjadi "guest", mengingat saat ini tidak ada solusi politik yang akan mengarah pada berakhirnya konflik di Suriah. Pada akhirnya, Turki menilai kembali kebijakan tersebut karena meningkatnya ancaman keamanan, termasuk pemboman yang menyebabkan kematian warga sipil Turki di wilayah perbatasan.

Meskipun pembuat kebijakan tidak benar-benar mengaitkan insiden perbatasan tersebut dengan kedatangan Suriah, namun skala kedatangan mencapai tingkat yang "menyusahkan" untuk Turki mengendalikan sendiri. Sebagai tanggapan, Turki mengambil beberapa langkah, termasuk "zero-point delivery" yaitu, pemberian bantuan kemanusiaan di perbatasan. Namun inisiatif ini tidak menghentikan aliran pengungsi yang masuk dan akhirnya, pada akhir tahun 2012, Turki menghentikan kebijakan open door. Masuknya Suriah sekarang hanya diizinkan melalui penyeberangan perbatasan resmi, dan tergantung pada tempat-tempat yang tersedia di kamp atau pada kebutuhan kemanusiaan yang mendesak (Human Rights Watch, 2014).

Namun, keputusan tersebut memberikan dampak pada meningkatnya pengungsi yang tidak memiliki dokumen. Pengungsi tersebut yang berasal dari negara-negara yang kurang stabil secara ekonomi dan politik seperti Afganistan, Pakistan, dan Suriah yang menggunakan Turki sebagai negara tujuan maupun sebagai "negara transit" untuk melanjutkan perjalanan mereka ke Eropa. Meningkatnya kedatangan pengungsi yang tidak berdokumen telah menjadi isu utama di Turki.

Adanya pengungsi yang tidak berdokumen dianggap menimbulkan ancaman seperti keamanan untuk Turki, tidak hanya alasan keamanan, tetapi juga alasan ekonomi dan juga politik terhadap negara dan juga masyarakat Turki. Pada tahun 2013 dan 2014, mulai mengeluarkan kebijakannya tentang menangani pengungsi yang tidak berdokumen tersebut melalui Law on Foreigners and International Protection (LFIP) ditahun 2013, dan Temporary Protection Regulation (TPR) ditahun 2014. Pada saat yang sama, pemerintah membangun sebuah badan terpisah yaitu the Directorate General of Migration Management (DGMM), didirikan untuk mengelola urusan migrasi.

Meskipun konflik yang berkepanjangan di Suriah hingga saat ini belum menemukan tandatanda adanya perdamaian antara kedua kubu, konflik ini telah membawa masalah besar yaitu adanya krisis pengungsi. Krisis pengungsi ini sama seperti sebelumnya di mana Turki sebagai negara yang terkena dampak dari adanya pengungsi. Namun, ketika kebijakan tersebut pertama kali diterapkan, para pengungsi ini awalnya dianggap hanya sebagai "guest", bukan pengungsi. Hal ini dikarenakan adanya batasan geografis pada Geneva Convention 1951 yang berkaitan dengan status pengungsi yang dipertahankan oleh Turki yang membatasi status pengungsi hanya bagi mereka yang datang dari Eropa (Togral Koca, 2015). 
Sekalipun demikian, Turki tetap memberikan fasilitas yang memudahkan pengungsi Suriah. Seperti, Turki memberikan kemudahan untuk mengakses dan menyewa tempat tinggal di seluruh wilayah Turki, memberi keluarga kartu debit yang dapat mereka gunakan untuk membeli barangbarang pasar di dalam kamp, bahkan memberikan keleluasaan bagi pengungsi untuk mencari tempat kerja di Turki, akan tetapi dengan memberikan peluang bagi pengungsi untuk memperoleh pekerjaan menyebabkan tersebarnya tenaga kerja yang murah di Turki (Amnesty International, 2014).

Keseriusan Turki dalam mengatasi krisis pengungsi terlihat dengan Turki menyediakan kamp-kamp pengungsian. Warga Suriah yang datang ke Turki yang berniat untuk tetap berada di luar kamp dapat tinggal di provinsi mana pun yang mereka sukai, tetapi mereka harus mendaftar di kota tempat mereka tinggal untuk mengakses layanan publik (Icduygu dan Simsek, 2016).

\section{Kerja Sama Uni Eropa dan Turki dalam Menangani Krisis Pengungsi}

Adanya pengaruh geopolitik dan strategis Turki menjadikan negara tersebut sebagai aspek penting dari kebijakan migrasi Uni Eropa meskipun bukan negara anggota UE. Turki, negara kandidat UE sejak 1999, telah bekerja sama dengan Uni Eropa untuk mengontrol arus migran dan pengungsi dari Timur. Sejak Desember 2013, Uni Eropa telah menawarkan untuk berbagi beban bersama dalam bentuk kesepakatan mengingat Uni Eropa merupakan tujuan utama pengungsi tersebut. Kesepakatan tersebut kemudian memengaruhi tata kelola migrasi ilegal Turki dengan caracara baru. The EU-Turkey Readmission Agreement, tentang penerimaan kembali orang-orang yang tinggal tanpa otorisasi. Kesepakatan ini menetapkan ketentuan terkait penerimaan kembali warga negara dari negara-negara anggota Uni Eropa dan Turki. Seperti penerimaan kembali warga thirdcountry nationals dan orang-orang tanpa kewarganegaraan yang telah memasuki, atau tinggal di, wilayah masing-masing pihak yang secara langsung tiba dari wilayah pihak lain (European Commission, 2013).

Kesepakatan tersebut bersamaan dengan dimulainya the Visa Liberalisation Dialogue (VLD) yang bertujuan untuk penghapusan kewajiban visa yang dikenakan pada warga Turki yang bepergian ke daerah Schengen untuk kunjungan jangka pendek (European Commision, 2016). VLD didasarkan pada Road Map menuju rezim bebas visa dengan Turki. VLD adalah sebuah dokumen yang menjabarkan persyaratan yang harus dipenuhi Turki untuk memungkinkan Parlemen Eropa dan Dewan untuk mengubah peraturan yang akan memungkinkan warga negara Turki yang memegang paspor biometrik yang sesuai dengan standar Uni Eropa. Paspor tersebut nantinya digunakan untuk bepergian ke Negara Anggota Schengen tanpa visa untuk masa tinggal singkat yaitu dalam jangka waktu 90 hari sampai 180 hari, dan mengizinkan warga negara dari Negara Anggota Uni Eropa yang masih membutuhkan visa untuk masa tinggal singkat untuk memasuki Turki dengan bebas visa perjalanan (Delegation of the European Union to Turkey, 2013).

Adanya kesepakatan tersebut sebagai sebuah jalan baru Turki untuk mengatasi masalah pengungsi yang ada di Turki dan sebagai awal baru untuk melanjutkan proses aksesi untuk Turki yang sempat terhenti. Bagi negara transit seperti Turki, hubungan dan penawaran dengan negara tujuan yang termasuk dalam domain kebijakan luar negeri sangat penting. Eropa adalah daerah tujuan utama bagi migran gelap yang menggunakan Turki sebagai negara transit, dan karena itu rezim pengungsi tidak teratur Turki tidak dapat lepas dari dampak kebijakan Uni Eropa. 
Uni Eropa telah melakukan pendekatan utama dalam pengendalian pengungsi yang tidak teratur ini, melalui kendali jarak jauh. Sebagai bagian dari pendekatan kendali jarak jauh, Uni Eropa memprioritaskan eksternalisasi kontrol perbatasan atau pembagian beban perbatasan Eropa dengan negara-negara yang berbatasan, dan pengaturan kebijakan manajemen migrasi di negara asal, dan terutama migrasi ilegal, mengikuti kepentingan Eropa (Aras dan Mencutek, 2018). Pada tahun 2014 yang merupakan starting point peningkatan jumlah pengungsi yang masuk ke Uni Eropa (Aydin, 2016). Tahun tersebut juga menjadi sebuah titik balik ketika terjadi peningkatan imigran yang tidak berdokumen dan tingkat kematian migran di perbatasan eksternal Uni Eropa, kejadian ini yang kemudian dikenal secara global sebagai krisis pengungsi Eropa. Menanggapi krisis tersebut, Komisi Eropa menerbitkan Agenda Eropa tentang Migrasi pada tahun 2015 yang bertujuan untuk mengatasi tantangan krisis tersebut dan sebagai alat untuk mengelola migrasi dan juga pengungsi dengan lebih baik dalam jangka menengah dan panjang di bidang migrasi tidak teratur, pengungsi, dan migrasi legal (European Commision, 2015). Agenda tersebut diikuti dengan adanya joint action plan antara Turki dan Uni Eropa pada 18 Maret 2016. Kesepakatan ini memiliki banyak ambisi, yang paling jelas dimaksudkan untuk mengurangi tekanan di perbatasan Eropa dan menghalangi pencari suaka dan migran di masa depan untuk melakukan perjalanan mencegah aliran pengungsi yang datang ke Uni Eropa (European Council, 2016).

Kesepakatan tersebut diperkenalkan sebagai alat kebijakan baru. Dengan pernyataan tersebut, Dewan Eropa dan Turki menyepakati tiga tujuan utama yaitu mencegah hilangnya nyawa di Laut Aegea, memutus jaringan penyelundupan migran, dan mengganti migrasi ilegal dengan migrasi legal. Menurut Pasal 1 Pernyataan tersebut, Turki setuju untuk menerima pengembalian semua migran yang tidak membutuhkan perlindungan internasional yang menyeberang ke Yunani setelah 20 Maret 2016 dan untuk mengambil kembali semua migran gelap yang telah dicegat di perairan Turki (European Commission, 2015). Selain itu agenda yang akan menjadi tujuan utama dalam penerapan Joint Action Plan yaitu menekankan pada upaya dan tindakan dari Uni Eropa berupa pemberian bantuan berupa bantuan finansial, memberikan pembebasan visa Schengen terhadap warga negara Turki untuk bisa memasuki wilayah schengen, serta membuka kembali proses aksesi Turki untuk bisa berintegrasi dengan Uni Eropa yang sempat terhenti pada tahun 2016 (Noermanita, 2017).

Kesepakatan ini merumuskan peraturan yang dikenal sebagai formula "one to one", yang menyatakan bahwa untuk setiap warga Suriah yang kembali ke Turki dari pulau-pulau Yunani, akan dikembalikan ke Uni Eropa, hingga maksimal 72.000 orang (Pasal 2). Pernyataan itu juga menyebutkan peningkatan serikat dan memberi energi kembali proses aksesi bagi Turki untuk mendapatkan keanggotaan penuh. Insentif yang ada dalam kerangka eksternalisasi, seperti dukungan pengembangan kapasitas dan bantuan keuangan, juga dimasukkan, tetapi dengan syarat yang lebih murah hati (Sert dan Turkmen, 2017).

Hasil dari kerjasama antara Uni Eropa dan Turki adalah rencana untuk membangun tembok sepanjang 911 kilometer di sepanjang perbatasan Turki-Suriah, sebuah rencana yang secara resmi diperkenalkan ke kabinet Turki pada Juli 2015. Inisiatif ini merupakan respons terhadap peningkatan risiko keamanan perbatasan yang telah diperburuk dengan adanya pengungsi yang tidak berdokumen. Sejalan dengan action plan, konstruksi dinding tersebut telah dimulai, dengan rencana lebih lanjut untuk meningkatkannya melalui kendaraan pengintai dan pusat komando dan kontrol yang terintegrasi (Moldovan, 2017). 
Inisiatif ini memiliki kesamaan dengan sistem Frontex Uni Eropa yaitu dukungan teknis tambahan untuk negara-negara Uni Eropa yang menghadapi tekanan migrasi yang parah. Adanya sistem tersebut untuk manajemen perbatasan eksternal dengan sistem pengawasan berteknologi tinggi yaitu Eurosur, yang merupakan bagian dari sistem manajemen perbatasan terintegrasi Uni Eropa (European Union, 2004). Kerjasama ini membangun perbatasan antaran kedua belah wilayah memberikan sebuah underline bagi peran Turki yang lebih berperan besar dalam mengurangi tingkat kedatangan pengungsi ke Uni Eropa. Faktanya Turki telah meminimalkan tekanan migrasi di perbatasan luar Eropa yang dengan perjanjian UE-Turki pada Maret 2016, migrasi ilegal telah dihentikan sebelum gerbang Eropa rampung, seperti jumlah kedatangan pengungsi di laut Yunani berkurang 97 persen dibandingkan tahun 2015 (Weber, 2018).

Meskipun demikian, kesepakatan tersebut menerima kritik karena kelemahan moral dan ketidaksesuaiannya dengan hak asasi manusia dan hukum pengungsi. Menurut Rossi dan Lafrate (2017), kesepakatan itu tidak sepenuhnya menghormati dan mematuhi konvensi internasional tentang pengungsi dan pencari suaka. Legalitas kesepakatan itu dipertanyakan ketika Pengadilan Eropa menolak klaim tiga pencari suaka atas dasar bahwa itu tidak dicapai oleh lembaga Uni Eropa, tetapi secara bilateral oleh masing-masing negara anggota dengan Turki. Agar pelanggaran tersebut dinyatakan sah, arahan Eropa tentang prosedur suaka telah diperpanjang dan Komisi Eropa mengkategorikan Turki sebagai negara yang aman yang berarti bahwa migran gelap, pencari suaka yang ditolak, warga Suriah dan pencari suaka lainnya di bawah perlindungan sementara dapat dikembalikan ke Turki, tempat mereka dapat menemukan perlindungan dan aman. Namun, klasifikasi Turki sebagai "negara aman" memicu perdebatan.

Menurut Roman et al. (2016), ada tiga alasan mengapa Turki tidak memenuhi syarat sebagai negara "aman". Pertama, pencari suaka dan pengungsi menghadapi ketidakpastian terkait situasi hukum mereka, dan Turki tidak memberikan status hukum penuh kepada pengungsi yang datang dari luar Eropa atau yang berada di bawah rezim perlindungan sementara terutama untuk warga Suriah. Kedua, Turki memberikan Suriah hak untuk bekerja, namun pada kenyataannya sangat sedikit warga Suriah yang benar-benar telah memperoleh izin kerja. Ketiga, Turki juga memiliki catatan memperlakukan pencari suaka dan pengungsi dengan keras di tahanan. Pencari suaka atau pengungsi yang terdaftar dapat ditempatkan di tahanan karena gagal mematuhi prosedur paralel untuk pencari suaka non-Eropa atau mencoba memasuki Yunani secara ilegal (Roman, Baird, dan Radcliffe, 2016).

Meskipun memicu perdebatan, action plan antara Uni Eropa dan Turki tetap berjalan dan telah memenuhi tujuan utamanya seperti secara substansial membatasi jumlah kedatangan di Yunani dan mencegah pergerakan mereka selanjutnya untuk datang ke Eropa. Pada tahun 2015, ada 885.400 orang penyeberangan perbatasan yang tidak teratur melalui Rute Mediterania Timur dan pada tahun 2016 hanya 182.537 orang yang tercatat (UNHCR, 2016).

\section{Ketidaksesuaian Joint Action Plan}

Kaya (2020) menyebutkan Uni Eropa memiliki dua strategi tersembunyi di bawah pendekatan kemanusiaannya. Pertama, kesepakatan pengungsi dengan Turki membantu UE untuk mewujudkan tanggung jawab perlindungannya dengan biaya lebih rendah dengan mengalihkan tanggung jawab perlindungan pengungsinya ke Turki dengan peluang pemukiman kembali yang terbatas dan dukungan keuangan. Kedua, perjanjian penerimaan kembali dengan praktik negara 
ketiga yang aman adalah permainan berbagi beban yang dimainkan oleh UE untuk mengalihkan tanggung jawab hukum dan kemanusiaan mereka ke negara-negara lain yang kurang berkembang.

Sebelumnya, Lavenex (1998) telah berpendapat bahwa Eropa tidak menanggapi prinsipprinsip global perlindungan pengungsi internasional yang didasarkan pada gagasan solidaritas internasional dan pembagian beban, tetapi lebih banyak membentuk sistem pengalihan beban atau redistribusi negatif yang mengalihkan tanggung jawab perlindungan pengungsi kepada negara di timur dan selatan.

Hubungan strategis antara Uni Eropa dan Turki menimbulkan beberapa aspek negatif dalam jangka panjang dan terkesan hanya bersifat satu arah, dimana hanya Uni Eropa yang merasakan dampaknya, sedangkan kesepakatan tersebut didasarkan pada prinsip timbal-balik. Hal ini terlihat ketika jumlah pengungsi yang tidak berdokumen yang ditangkap meningkat, dari 174.466 orang pada 2016 kemudian naik sebanyak 175.752 orang ditahun 2017. Pada tahun 2019, terjadi peningkatan yang secara substansial sebanyak 454.662 orang (lihat gambar 2) (DTM, 2020). Adanya hal tersebut menunjukkan bahwa, action plan ini terkesan memperlihatkan untuk mendukung tujuantujuan Uni Eropa, berfokus pada pencegahan keluarnya migran ilegal dan pencari suaka Timur Tengah, daripada mencegah masuk ke Turki.

\section{Gambar 2. Pengungsi Tidak Berdokumen di Turki.}

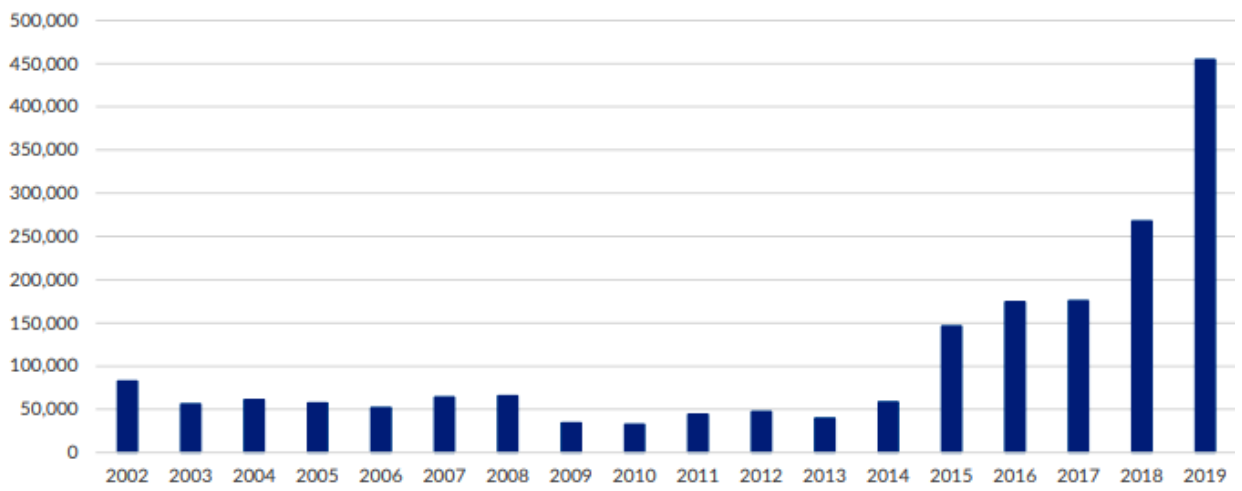

Sumber: DTM IOM, 2020.

Pada 5 September 2019, Presiden Erdogan mengeluarkan ancamannya terhadap Uni Eropa untuk membuka pintu perbatasan ke Eropa bagi para pengungsi Suriah. Turki menuduh Uni Eropa belum membayar bantuan dana yang telah disepakati, yaitu 6 miliar USD. Presiden Erdogan menyatakan bahwa sejauh ini hanya 3 miliar USD yang telah diterima dari Uni Eropa untuk merawat para pengungsi Suriah, hal ini tidak sebanding dengan Turki yang telah menghabiskan 40 miliar USD. Pada akhirnya, Turki mengklaim bahwa mereka hanya menerima sebagian kecil dari dukungan keuangan yang dijanjikan dari Uni Eropa. Presiden Erdogan melanjutkan bahwa Turki akan berbagi “beban” bersama-sama dengan membuka perbatasan ke Eropa (Mahmet, 2019).

Ancaman ini didasarkan belum terpenuhinya janji-janjinya dalam hubungan bilateral. Hal ini terlihat dalam bantuan keuangan yang dijanjikan kepada Turki. Meskipun ada perselisihan teknis tentang pembayaran 6 miliar Euro dari UE ke Turki seperti waktu pembayaran dan permintaan transparansi UE untuk memastikan uang tersebut langsung masuk ke pengungsi Suriah, kesepakatan itu berjalan relatif lancar tetapi dengan beberapa penundaan. Dana Uni Eropa sebesar 
3 miliar EUR untuk 2016-2017 telah dicairkan sementara dari sisa 3 miliar EUR untuk 2018-2019 hampir semuanya telah dialokasikan, setengahnya telah dikontrak, dan hampir sepertiga telah dicairkan (Dagi, 2020).

Pemerintah Turki sering menunjukkan ketidakpuasannya terhadap jumlah dan cara pengalokasiannya. Bahkan komitmen 6 miliar EUR dari uang pembayar pajak UE tidak banyak membantu Turki yang menurut angka resmi telah menghabiskan sekitar 40 miliar USD untuk pengungsi Suriah di tengah tingkat pengangguran yang tinggi dan ekonomi dalam resesi (Doga, 2020).

Proses aksesi menemui jalan buntu dalam jangka panjang. Alasan mendasar di balik ini adalah karena Uni Eropa dapat bekerja sama dengan Turki tanpa keanggotaan, tidak ada insentif untuk mengintegrasikan Turki ke dalam Uni Eropa sebagai anggota. Dengan kata lain, kerja sama strategis baru ini mencegah tercapainya hasil yang utuh dalam hubungan UE-Turki dalam jangka panjang (Hoffman dan Werz, 2019). Dalam tulisan Gammeltoft-Hansen (2011) berpendapat bahwa mengalihkan tanggung jawab perlindungan pengungsi ke negara-negara kurang berkembang merupakan langkah untuk mencapai 'mekanisme hak pasar', di mana perlindungan diwujudkan dengan biaya serendah mungkin.

Pada 13 Maret 2019, Parlemen Eropa menangguhkan negosiasi aksesi UE dengan Turki. Menunjuk pada 'kemunduran politik dan demokrasi', dengan suara terbanyak mendukung penangguhan pembicaraan aksesi dengan Turki (European Parliament, 2020). Penangguhan ini tidak terlepas kekhawatiran Negara-negara anggota Uni Eropa terhadap Turki tentang migrasi dan terorisme. Bahkan banyak kaum konservatif Eropa menentang aksesi Turki karena ukuran dan perbedaan budaya atau agama penduduk Turki (Hoffman dan Werz, 2019).

Selain itu, janji pembebasan visa bagi warga Turki juga belum terwujud. Dalam laporan terbaru Komisi Uni Eropa, Turki belum memenuhi tolak ukur liberalisasi visa, yang berarti bahwa negara tersebut masih perlu menyelaraskan undang-undangnya dengan Uni Eropa mengenai kebijakan visa. Ada lima kriteria yang harus dipenuhi Turki yaitu pemberantasan korupsi, mematuhi standar UE tentang undang-undang data pribadi, melakukan perjanjian operasional dengan Europol, menawarkan kerja sama yudisial yang efektif kepada Negara-negara Anggota UE mengenai masalah kriminal, dan merevisi praktik undang-undang tentang terorisme sesuai dengan standar UE (Council of the European Union, 2021).

Pada 28 Februari 2020, Presiden Erdogan mengumumkan keputusan untuk mengizinkan pengungsi dan migran secara bebas melintas yang mendorong puluhan ribu pengungsi untuk menyeberang ke Eropa melalui Yunani. Menteri Dalam Negeri Turki, Süleyman Soylu, mengumumkan pada 1 Maret bahwa sekitar 76.000 orang sedang menuju ke Yunani. Menurut Cortinovis (2021), pihak berwenang Turki secara proaktif memfasilitasi pergerakan migran ke daerah perbatasan dengan menyediakan transportasi bus gratis dan menginstruksikan migran untuk berjalan menuju sungai Evros.

Selama tahun 2020, Turki telah menampung 3,65 juta pengungsi dan pengungsi yang berasal dari Suriah sebanyak 3,64 juta (UNHCR, 2021). Menampung lebih banyak pengungsi daripada negara lain mana pun, Turki telah mencapai titik kritis dalam kebijakan migrasinya beberapa bulan lalu. Dalam sebuah konferensi pers tanggal 29 Agustus 2021, Menteri Luar Negeri Turki, Mevlut Cavusoglu, menyatakan bahwa Turki tidak dapat lagi menanggung masuknya migran dan bahwa Perjanjian Uni Eropa-Turki 2016 perlu direvisi (Euractiv, 2021). 
Masalah ini kemudian diangkat dalam Presiden Erdogan Pada tanggal 14 September 2021, Presiden Erdogan juga mengangkat masalah ini dalam percakapan telepon dengan Presiden Jeerman, Jerman Frank-Walter Steinmeier. Presiden Erdogan menekankan bahwa Turki mengharapkan UE untuk menerapkan kesepakatan migrasi UE-Turki 2016 dengan "semua dimensinya" serta "mengambil langkah dengan cepat" untuk memulai kembali pembicaraan aksesi, untuk memperbarui serikat pabean dan memberikan izin masuk bebas visa kepada warga Turki (Camlibel et.al, 2021).

\section{Kesimpulan}

Dalam penelitian ini, penulis menemukan bahwa kesepakatan ini terlihat "rapuh" dengan semakin mendorong adanya saling ketergantungan pada pemeliharaan hubungan politik di antara kedua negara. Pada dasarnya, action plan antara Uni Eropa dan Turki merupakan sebuah mekanisme baru untuk "pemulangan" pengungsi dan eksternalisasi kontrol migrasi ke negara-negara transit. Turki adalah salah satu negara tujuan bagi pengungsi, migran gelap dan bahkan bagi pencari suaka. Perjanjian penerimaan kembali dengan negara-negara transit, sebagaimana terbukti dari perjanjian Uni Eropa-Turki, dapat berfungsi dengan baik sebagai alat pencegahan bagi para pengungsi yang terbukti jumlah penyeberangan menurun secara substansial setelah implementasinya.

Menurut penulis, adanya kerja sama kesepakatan Uni Eropa dan Turki tersebut semakin membuat hubungan kedua negara bertumpu pada kondisi kerja sama yang tidak menguntungkan. Selama beberapa tahun terakhir terjadi adanya erosi kepercayaan di antara kedua negara. Kepercayaan yang dapat didefinisikan sebagai 'harapan kerja sama dan timbal balik', semakin tidak terlihat dalam hubungan kedua negara khususnya Turki. Sumber ketidakpercayaan terlihat dalam ambiguitas jangka panjang mengenai prospek aksesi Turki yang dipicu aturan eksklusif para pemimpin Eropa terhadap Turki. Hal ini semakin membuat action plan tersebut terkesan hanya bertindak sebagai mekanisme untuk mentransfer beban manajemen pengungsi ke Turki.

Penelitian ini diharapkan bisa memberikan wawasan baru mengenai hubungan kerjasama antara negara dan organisasi antar negara dalam menangani isu pengungsi serta dampak yang ditimbulkan dari adanya kesepakan dalam kerjasama tersebut. Disisi lain penelitian ini akan mendorong penelitian lanjutan di bidang kajian Hubungan Internasional kontemporer mengingat isu pengungsi merupakan isu kontemporer yang hingga saat ini permasalahannya semakin komplek dan berdampak pada suatu negara dalam berbagai bidang.

\section{Referensi}

Abdelaaty, Lamis. 2019. Refunge and Guesthood in Turkey'. Journal of Refuuge Studies. Vol. 0, No. 0. Oxford University [download] dari https://academic.oup.com/jrs/advance-articleabstract/doi/10.1093/jrs/fez097/5625572

Aras, Nefise Ela Gokalp dan Zeynep Sahin Mencutek, 2018. "Evaluation of irregular migration governance in Turkey from a foreign policy perspective". Article in New Perspective on Turkey. Volume 53, 63-88.

Aydin, Ulviyye. 2016. 'The Syirian Refugee Crisis: New Negotiation Chapter In European Union - Turkey Relations'. Khazar Journal of Humanities and Social Science, 19 (2).

Betts, Alexander. 2011. International Cooperation in the Refugee Regime (pp. 53-84) in Alexander Betts and Gil Loescher. Refugees in International Relations. Oxford: Oxford University Press. 
Camlibel, Cansu, Onder Agledik, Sezin Oney, dan Bahadir Ozgur. 2021. Turkey cannot handle new refugee influx, Erdoğan tells German counterpart [online] in https://www.duvarenglish.com/turkey-cannot-handle-new-refugee-influx-erdogan-tellsgerman-counterpart-steinmeier-news-58817 [diakses pada 19 November 2021]

Cetin, Sefa, Erol Turan, dkk. 2017. The Impact Of The Syirian Refugee Crisis on Turkey-EU Realtion. International Journal of Political Studies. 3(3).

Cortinovis, Roberto. 2021. Pushbacks and lack of accountability at the Greek-Turkish borders. Liberty and Security. CEPS Paper.

Council of the European Union. 2021. Statement of the members of the European Council, 25 March 2021 [download] in https://www.consilium.europa.eu/en/press/pressreleases/2021/03/25/statement-of-the-members-of-the-european-council-25-march2021/\# [diakses pada 19 November 2021]

Dagi, Dogachan. 2020. The EU-Turkey Migration Deal: Performances dan Prospects. European Foreign Affairs Review, 25 (2), 197-216.

Delegation of the European Union to Turkey, 2013. "Visa Liberalisation Dialogue" [online] in https://www.avrupa.info.tr/en/visa-liberalisation-dialogue-6896 [diakses pada 3 Januari 2020].

Diez, Thomas, Ingvild Bode, dan Aleksandra Fernandes da Costa. 2011. Key Concepts in International Relations. London: Sage Publications.

Displacement Tracking Matrix. 2020. Migrant Presence Monitoring: Quarterly Report Q2 2020 [download] in https://dtm.iom.int/reports/turkey- $\% \mathrm{E} 2 \% 80 \% 94$-migrant-presencemonitoring-yearly-report-2020 [diakses pada 15 November 2021]

Eck, Daniel, 2019. "Turkey suspends deal with the EU on migrant readmission" [online] in https://www.euractiv.com/section/global-europe/news/turkey-suspends-deal-with-theeu-on-migrant-readmission/ [diakses pada 10 Januari 2020].

Euractiv. 2021. Turkey cannot take new refugee burden, foreign minister says [online] in https://www.euractiv.com/section/global-europe/news/turkey-cannot-take-new-refugeeburden-foreign-minister-says / [diakses pada 19 November 2021]

European Commision. "Common European Asylum System" [online] in https://ec.europa.eu/home-affairs/what-we-do/policies/asylum_en [diakses pada 29 Desember 2019].

European Commission, 2015. "European Agenda on Migration" [online] in https://ec.europa.eu/home-affairs/what-we-do/policies/european-agenda-migration_en [diakses pada 4 January 2020]

European Commission, 2013. "EU-Turkey Readmission Agreement signed and Visa Liberalization Dialogue launched" [online] in https://ec.europa.eu/home-affairs/what-isnew/news/news/2013/20131216_01_en [diakses pada 3 Januari 2020]

European Comision, 2015. "EU-Turkey joint action plan" [online] in https://ec.europa.eu/commission/presscorner/detail/en/MEMO_15_5860 [diakses pada 29 Desember 2019].

European Council, 2016. "EU-Turkey statement, 18 March 2016" [online] in https://www.consilium.europa.eu/en/press/press-releases/2016/03/18/eu-turkeystatement/ [diakses pada 4 January 2020].

European Union, 2004. "European Border and Coast Guard Agency (Frontex)" [online] in https://europa.eu/european-union/about-eu/agencies/frontex_en [diakses pada 5 Januari 2020].

European Commision. 2016. REPORT FROM THE COMMISSION TO THE EUROPEAN PARLIAMENT AND THE COUNCIL: Third Report on progress by Turkey in fulfilling the 
requirements of its visa liberalisation roadmap [download] in https://ec.europa.eu/transparency/regdoc/rep/1/2016/EN/1-2016-278-EN-F1-1.PDF [diakses pada 11 Januari 2020]

European Parliament. 2020. Parliament wants to suspend EU accession negotiations with Turkey [online] in https://www.europarl.europa.eu/news/en/press-room/20190307IPR30746/parliamentwants-to-suspend-eu-accession-negotiations-with-turkey [diakses pada 15 November 2021]

Gammeltoft-Hansen, Thomas. 2011. Outsourcing Asylum: The Advent of Protection Lite in Luiza Bialasiewicz (ed), Europe in the World: EU Geopolitics and the Making of European Space. London: Routledge.

Greenhill, Kelly M, 2016. "Migration as a Weapon in Theory and in Practice". Millitary Review. 96 (6). 23-36.

Hammarberg, K., M. Kirkman1, dan S. de Lacey. 2016. Qualitative research methods: when to use them and how to judge them. Human Reproduction, 31(3), 498-501.

Harrison, Lisa dan Theresa Callan. 2013. Key Research Concepts In Politics and International Relations. London: SAGE.

Hasenclever, Andreas, Peter Mayer, dan Volker Rittberger.Theories of international regimes. New York: Cambridge University Press.

Icduygu, Ahmet. 2000. The Politics of International Migratory Regimes: Transit Migration Flows in Turkey. International Social Science Journal, 52(165), 357-367.

Icduygu, Ahmet. 2003. Irregular migration in Turkey (IOM migration research series, no. 12). Geneva: IOM [download] in https://publications.iom.int/system/files/pdf/mrs_12_2003.pdf [diakses pada 21 Maret 2021]

Icduygu, Ahmet. 2013. Turkey and international migration 2012-13. Report. Migration Research Center at Koc University, Istanbul, November.

Icduygu, Ahmet dan Dogus Simsek. 2016. Syrian Refugees in Turkey: Towards Integration Policies. Turkish Policy Quarterly, 15 (3), 59-69.

International, Amnesty. 2014. 'Struggling to Survive-Refunge From Syiria in Turkey'. EUR 44/017/2014, hal:4, United Kingdom.

Hoffman, Max dan Michael Werz. 2019. The Effects of a Suspension of Turkey's EU Accession Process. Stiftung Mercator.

Human Rights Watch, 2014. "World Report 2014: Turkey" [online] in https://www.hrw.org/world-report/2014/country-chapters/turkey [diakses pada 5 Januari 2020].

Kaya, Hulya. 2020. The EU-Turkey Statement on Refugees: Assessing Its Impact on Fundamental Rights. UK: Edward Elgar Publishing Limited.

Khan, Waseem. 2018. Syria: History, The Civil War, and Peace Prospects. Journal of Political Studies, 24 (2), 587-601.

Koca, Burcu Togral, 2015. "Deconstructing Turkey's “Open Door” Policy towards Refugees from Suriah". Article in Migration Letters. 12 (3). 209-225.

Koca, Togral Burcu. 2016. Syrian refugees in Turkey: from "guests" to "enemies"?. New Perspectives on Turkey, 54, 55-75. doi:10.1017/npt.2016.4.

Lavenex, Sandra. 1998. Passing the Buck': European Union Refugee Policies towards Central and Eastern Europe. Journal of Refugee Studies, 11(2), 126-145. doi:10.1093/jrs/11.2.126.

Moldovan, Carmen. 2017. Is the EU-Turkey Action Plan an effective or just an apparent solution to the refugee crisis?. CES Working Papers, ISSN 2067-7693, Alexandru Ioan Cuza University of Iasi, Centre for European Studies, Iasi, 9(3), pp. 195-212. 
Nielsen, Selin Yildiz, 2016. "Perceptions Between Suriahn Refugees and Their Host Community". Turkish Policy. 15 (3), 100-107.

Noermanita, Eka. 2017. 'Analisis Kebijakan Luar Negeri Turki Terbadap Kerjasama Turki dan Uni Eropa Mengenai Pengungsi Suriah'. Global \& Policy, 5 (1). Universitas Pembangunan Nasional Veteran Jawa Timur.

Olanrewaju, faith \& Segun Joshua. 2015. 'The Diplomatic Dimentions of The Syirian Conflict'. Jadavpur Journal of International Relations. 19(3). Hal: 43-63.

Olejarova, Barbora. 2018. The Great W all of Turkey: From „The Open-Door Policy” to Building Fortress?. Pogranicze Polish Borderlands Studies, 6 (2), 117-133.

Pertiwi, Lunyka Adelina. 2016. 'Kompleksitas Rezim di Uni Eropa: Upaya Penanganan Pengungsi dan Pencari Suaka'. Jurnal Ilmu Sosial dan Ilmu Politik, 19 (3).

Putri, Amalia Zatalini Kusuma. 2015. 'Kebijakan Turki Dalam Menampung Korban Perang Saudara Suriah Tabun 2011-2013'. Journal Of International Realtion, Vol: 1, No: 1. Universitas Diponegoro. Hal: 1-15.

Sert, Deniz Senol dan Fulya Felicity Turkmen, 2017. "The EU-Turkey Refugee Deal: The "Disturbing" Balance between Protecting Refugee and Human Rights and Controlling Refugee Flows" in A. Giannakopoulos, ed. Solidarity in the European Union: Challenges and Perspectives: 31-39. Tel Aviv: Tel Aviv University.

Syafitri, Maisyita. 2017. Upaya Pemerintah Turki dalam Menanggulangi Pengungsi Dari Suriah Tabun 2014-2016'. JOM FISIP, 4 (2).

Mahmet, Fatih Hafiz, 2019. "EU: Sum paid for refugees in Turkey must be clarified" [online] in https://www.aa.com.tr/en/europe/eu-sum-paid-for-refugees-in-turkey-must-beclarified/1578213 [diakses pada 10 Januari 2020].

Roman, Emanuella, Theodore Baird, dan Talia Radcliffe, 2016. "Analysis Why Turkey is Not a "Safe Country" [online] in http://www.statewatch.org/analyses/no-283-why-turkey-is-nota-safe-country.pdf [diakses pada 8 Januari 2020].

Rossi, Enzo dan Paolo Lafrate, 2017. “The EU Agreement with Turkey: Does it Jeopardize Refugees' Rights?" [online] in https://cmsny.org/publications/rossi-iafrate-eu-turkeyagrmt/ [diakses pada 7 Januari, 2020].

Ulber, Silalahi. 2012. Metode Penelitian Sosial. Bandung: PT. Refika Aditama.

UNHCR. 2019. Turkey Fact Sheet 2019. Didownload dari https://reliefweb.int/report/turkey/unhcr-turkey-fact-sheet-july-2019 [diakses pada 21 Maret 2021]

United Nations High Commissioner, 2016. "Mediterranian Situation" [online] in https://data2.unhcr.org/en/situations/mediterranean\# [diakses pada 8 Januari 2020].

United Nations High Commissioner. 2021. Turkey: September 2021 [download] in https://reliefweb.int/sites/reliefweb.int/ files/resources/Bi-

annual $\% 20$ fact $\% 20$ sheet $\% 202021 \% 2009 \% 20$ Turkey $\% 20$ ENG.pdf [diakses pada 20 November 2021]

United Nations High Commissioner for Refugees, 1951. "Convention and Protocol Relating to the Status of Refugees" [online] in https://www.unhcr.org/3b66c2aa10 [diakses pada 30 Desember 2019].

United Nations High Commissioner for Refugees, 2018. "Global Trends Forced Displacement in 2018” [online] in https://www.unhcr.org/5d08d7ee7.pdf [diakses pada 30 Desember 2018].

United Nations High Commissioner for Refugees, "THE 1951 CONVENTION relating to the Status of Refugees and its 1967 PROTOCOL” [online] in https://www.unhcr.org/aboutus/background/4ec262df9/1951-convention-relating-status-refugees-its-1967protocol.html [diakses pada 2 Januari 2020]. 
Copyright (C) 2021, Fitri Sholihin, Rama Fernandhy Alfan This is an open access article under the CC-BY-SA

license
ISSN 2088-8090 (Print) ISSN 2597-6648 (Online)

Sospol: Jurnal Sosial Politik Vol 7 No 2 (2021), pp.254-270

United Nations High Commissioner for Refugees, 2019. "Registered Suriahn Refugees" [online] in https://data2.unhcr.org/en/situations/Suriah/location/113 [diakses pada 1 Januari 2019].

Weaver, Matthew. 2017. "Suriahn refugees: more than $5 \mathrm{~m}$ in neighbouring countries now, says UN" [online] in https://www.theguardian.com/world/2017/mar/30/Suriahn-refugeenumber-passes-5m-mark-un-reveals [diakses pada 2 Januari 2020]

Weber, Manfred. 2018. 'EU - Turkey Relations need an Honest New Start'. Wilfried Martens Centre For European Studies, 17 (1).

World Bank. 2019. Turkey's Response to the Syrian Refugee Crisis and the Road Ahead [download] in https://www.worldbank.org/en/country/turkey/publication/turkeys-response-to-thesyrian-refugee-crisis-and-the-road-ahead [diakses pada 10 Januari 2020]

Yildiz, Ayselin Gozde. 2016. The European Union's Immigration Policy Managing: Migration in Turkey and Morocco. London: Palgrave Macmillan. 